\title{
The Subtleties of Speciesism
}

\author{
Jon Wynne-Tyson \\ Fontwell, Sussex, England
}

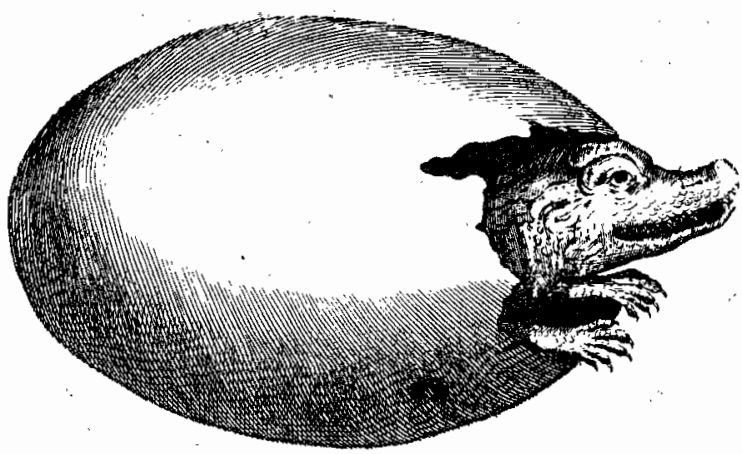

vocabulary, the term is already quite widely used, but perhaps too narrowly. For some it equates with little more than cruelty to animals or, more tamely, with a nonbenevolent attitude to other species. The dictionary definition is:

A prejudice or attitude of bias toward the interests of members of one's own species and against those of members of other species. A word used to describe the widespread discrimination that is practised by Homo sapiens against the other species.

There is no doubt that in the West we are increasingly aware of, and concerned about, our contributions to the suffering of other creatures. Many-understandably and often admirably - feel best able to express that concern by visible lobbying, demonstration, and all-important changes in personal lifestyle. Where sufficient pressure has been exerted, some individual and corporate acts of gross cruelty have been modified, and some changes in legislation effected. Some cosmetic companies, for a quiet life, have bowed to public revulsion over the better publicized examples of the most extreme cases of suffering inflicted for commercial profit; some furriers have gone out of business, if not voluntarily; some vivisectors, if not for the right reasons, are being seen to be more tolerant toward alternative methods of research; even some superstores, if again only to meet and profit by public demand, are making available less inhumanely procured food.

But should we convince ourselves that such welcome improvements are the beginning of an inevitable snowball? I suggest we cannot comfortably do so unless we promote equal attention to a better understanding of the full meaning and implications of "speciesism." Although a new addition to the Western

But the best words in a language are not those that merely pinpoint an object or a concept, but those that become an active humanizing tool by inserting the thin end of a wedge in our understanding. If we study and interpret the term "speciesism", it can deepen and enrich our view of the problem that has at last begun to engage human sympathy. "Problem," however, is too small a word. Our abuse of the environment shared by all sentient and non-sentient life is at last being seen as the major material challenge of our time, second only to that of reducing and controlling the human world population.

So far, so good. But within that concern for the environment, many feel that cruelty to animals is a relatively small matter that can be tidied up at a local

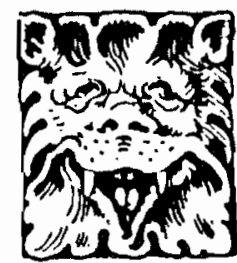

\section{COMMENT}


level and then put aside and forgotten. Yet all forms of life are connected:

For whatever happens to the beasts, soon happens to man... Whatever he does to the web, he does to himself. (Chief Seattle)

That interconnectedness is not sufficiently stressed in our present usage of the term "speciesism." It deserves a wider--if you like, higher-definition, a definition in which that interconnectedness is as much implied by the term "speciesism" as a sense of beauty is evoked by the term "flower" or "skyscape." We should come to employ it within contexts that emphasize its importance beyond a mere synonym for "cruelty to animals," in a manner that lifts the response from the pragmatic to the spiritual.

For cruelty to animals lies in our fundamental perception of animals, not just in the careless, thoughtless act of chasing, imprisoning, torturing and killing them. Those actions are more consequences of our belief in our superiority to animals, an arrogance so entrenched that the expression of our assumed superiority has not even been confined to exploitation of nonhumans. All through the sanguinary history of the human race, groups and nations have regarded themselves as superior to other groups and nations, to the extent that whites and blacks, Jews and Muslims, Scotsmen and Sassenachs, some would say even men and women, have effectively regarded each other as belonging, to all intents and purposes, to different species. Those taught to "waste" "gooks" in Vietnam were carefully and deliberately indoctrinated to see that country's peasants as of no more importance than the animals in the jungle. Here "speciesism" could have been said to mean not the conscious abuse of a different species, but an inability to distinguish between species.

In Speciesism: the Ethics of Animal Abuse, Richard D. Ryder has written: "If we as animals respect the interests of other individuals of our so-called speciesthen why not extend similar considerations to the other species also?" His very reasonable question highlights the point I am making - that we have gone so far down the road of violence and exploitation that we have got to rethink the concept of "The Species" from the standpoint of what is perhaps a greater concept; the concept of Kinship. For "we as animals" all too often do not "respect the interests of other individuals of our so-called species," and can it be denied that much of the reason for this is our age-old savagery to creatures weaker and less intelligent than ourselves?

"All things are connected." Indeed they are. Just as all love is, and implies, a connection, so all hate, envy and the pursuit of power is connected, building and sustaining an intangible but invasive web over the intricate affairs of humankind. And how easy it is, thoughtlessly and unintentionally, to add to that web. Most of us accept that all love is connected, for love is something we think about and want for ourselves. But how shallow is our thinking even on a matter so deeply implanted in the needs of our very being. All love is connected, yes, but to love each other in the fullest and most spiritual sense it is necessary that we achieve the easier task of loving those beings that do not harm or challenge us, and have only been the victims of our exploitation and callousness because our human cunning has preserved our role as the prime bullies of creation.

What weight can we give to love between humans if it has not stood the test of that more easily acquired love that is compounded of pity and empathy for those vast nations of vulnerable creatures whose lot has been so much worsened by the presence on this sad Earth of Homo sapiens? At its own level, loving our fellow humans is made easier than loving animals only by physical similarities and because human love is or can seem to be reciprocated. But "love" is too often and too easily a rationalisation of the procreative urge. Mutual attraction is all too readily mistaken for empathy, concurrence and shared aims.

This is not to say that loving, the "lesser" creatures is always that easy. Loving a squirrel that is getting at one's raspberries entails a different sense of kinship. There is a difficulty about discussing with a squirrel the concept of "speciesism," even if he could get his tongue round the word. In the squirrel's case we have to deal with our temptation to be speciesist by remembering that the squirrel genuinely believes (as well he might) that what we regard as ours are in fact his raspberries, nuts or cup of corn. If we can focus on the kinship concept deeply enough to lose the urge to hurl bricks at marauding squirrels, we are on our way to a philosophy that restrains us from wasting gooks or going into the Gulf with warships rather than considering the sanctional equivalents to wiring the raspberries.

Dear old Henry Salt said most of the things worth saying, and said them well. Like all who have thought 
deeply about human relationships, and their inextricable connection with other forms of sentient life, he encouraged the realisation of the unity of being:

To what sort of comfort can a person of sensibility hope to attain, in sight of the immense sum of wretchedness and suffering that is everywhere visible, and audible, around us? I know not a few humanitarians whose lives are permanently saddened by the thought of the awful destitution that afflicts large masses of mankind, and of the not less awful cruelties inflicted on the lower animals...it is useless to preach peace by itself, or socialism by itself, or antivivisection by itself, or kindness to animals by itself. The cause of each and all of the evils that afflict the world is the same - the general lack of humanity, the lack of the knowledge that all sentient life is akin, and that he who injures a.fellow being is in fact doing injury to himself...Only when the great sense of the universal kinship has been realized among us, will love cast out hatred. ${ }^{1}$

Poor Henry was not lucky in love, and perhaps that lack strengthened his perception of kinship. In the pyramid of language, "kinship" is a wider if a lesser word than love. If it has served its time, the moment is right to bring a deeper understanding to a term that has not so much taken the place of "kinship," as widened our perceptions to give a deeper and more empathetic understanding of the word "love."

"Speciesism" is not an easy word to handle, any more than is the concept it invites. If, in the more receptive climate of today, we can better comprehend and impart not only the full meaning but also the implications and imperatives of "speciesism," we shall have enriched and given greater meaning to the most undervalued and misinterpreted four-letter word in the English language.

\section{Notes}

${ }^{1}$ From Seventy Years Among Savages, quoted in The Extended Circle.

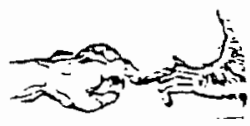

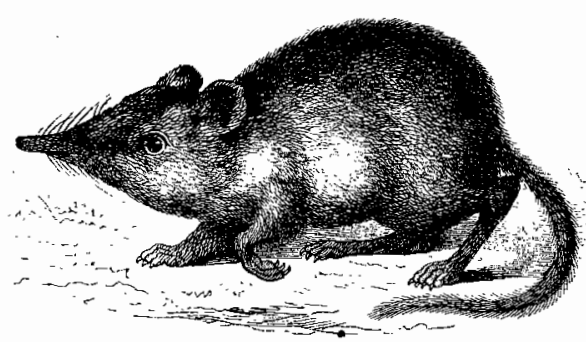

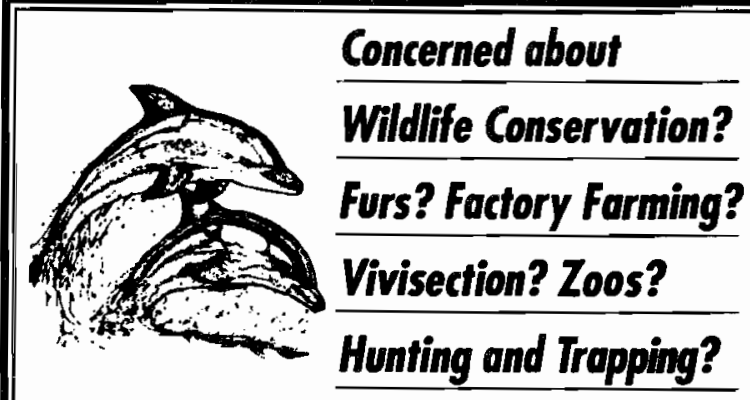

WE ARE TOO....

Did you know that philosophers have also made a contribution to the growth of the animal liberation movement? - Think of Regan, Singer, Clark, Magel, Rollin and Sapontzis.

Between the Species "is the only publication which allows such extensive examination of the philosophical basis for animal rights." - Brod Miller, Humane Forming Association

Subscribe today - and please send your tax deductible contribution -help us guarantee philosophers a forum in which to continue to evolve a sound basis for animal rights.

$\$ 16.00$ from

San Francisco Bay Institute

P.0. Box 254

Berkeley, CA 94701

Somple back issue $\$ 3.00$

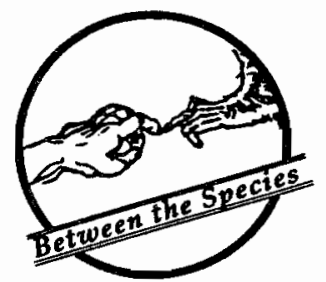

Quarterly Joumal of Ethics

\section{PHILOSOPHICAL ACTIVISM NEEDS YOUR SUPPORT!}

